\title{
NOTES
}

\section{Preparation and Properties of Aromatic Polyamides from 4,4"-o-Terphenyldicarbonyl Dichloride}

\author{
Yoshio Kasashima, Koji Yamamoto,* Nobuyuki Ando,* Fumihiko Akutsu,* \\ Kiyoshi NarUCHI,* and Masatoshi MiUra* \\ Graduate School of Science and Technology, Chiba University, \\ Yayoi-cho 1-33, Inage-ku, Chiba 263, Japan \\ * Department of Applied Chemistry, Faculty of Engineering, Chiba University, \\ Yayoi-cho 1-33, Inage-ku, Chiba 263, Japan
}

(Received June 9, 1994)

\begin{abstract}
KEY WORDS 4,4"-o-Terphenyldicarbonyl dichloride / Thermal Resistant Property / Solubility / Aromatic Polyamide /
\end{abstract}

Wholly aromatic polyamides are polymers with high thermal resistance. But, high softening temperatures or melting points and also poor solubility in many organic solvents make it difficult to fabricate. ${ }^{1}$ Therefore, research on the improvement of solubility has been carried out. We reported earlier the synthesis and properties of polyamides containing zigzag structures such as 2,3-quinoxalinediyl $1^{2,3}$ or 4,5-imidazolediyl ${ }^{4}$ units in their backbones. These polyamides have high thermal resistance and good solubilities in many organic solvents. In those reports, we suggested that the introduction of bulky, rigid and zigzag structures to the main chain of polyamides is effective for improving solubility while lowering thermal properties little, and that thermal properties of polyamides prepared from 2,3-bis(4-aminophenyl)quinoxaline were higher than those of the corresponding polyamide prepared from 4,4'-(2,3-quinoxaline)dibenzoic acid. In addition, we reported ${ }^{5}$ the preparation and characterization of aromatic polyamides 2 derived from 4,4"-diamino-o-terphenyl $\mathbf{1}$, which have high thermal properties and good solubility. But, polyamides prepared from $4,4^{\prime \prime}$-o-terphenyldicarboxylic acid ${ }^{6}$ or their derivatives have not been reported yet. Thus, in this report, the synthesis and properties of the polyamides 4 from 4,4"-o-terphenyldicarbonyl dichloride are investigated and the properties of 2 are compared with those of 4 .

\section{RESULTS AND DISCUSSION}

$4,4^{\prime \prime}-o$-Terphenyldicarbonyl dichloride 3 was prepared from $4,4^{\prime \prime}$-dibromo-o-terphenyl ${ }^{7}$ as the starting material according to the method reported by Rossa et al. ${ }^{6}$ The yield was $48.0 \%$.

Model reaction for the synthesis of polyamides was carried out with the use of aniline. The structure of the model compound was confirmed by spectroscopic data as well as by elemental analysis.

Poly(iminoaryleneiminocarbonyl-4,4" $-o$ terphenyldiylcarbonyl)s $(\mathbf{4 a - c})$ were prepared by low-temperature solution polycondensation $^{8}$ of diacyl dichloride 3 with aromatic diamines, e.g., $m$-phenylenediamine (a), p-phenylenediamine (b), 4,4'-oxydianiline (c). All polycondensations proceeded to homogeneous systems. The results of polycondensations are shown in Table I. The inherent viscosity of $\mathbf{4 a}$ prepared with propyl- 
Polyamides Containing 4,4"-o-Terphenyldiyl Unit

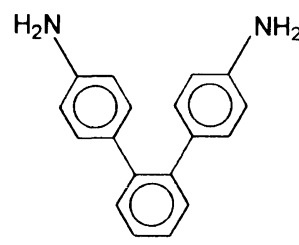

$\mathrm{CIOC}-\mathrm{Ar}-\mathrm{COCl}$

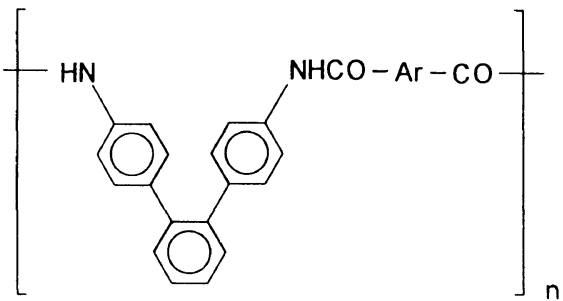

2

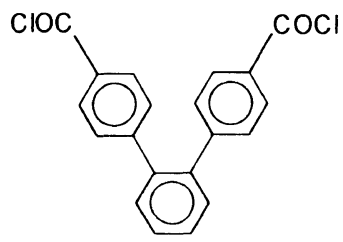

3
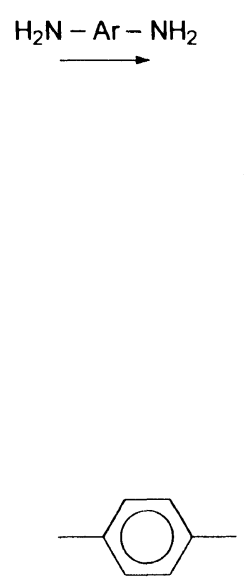

b

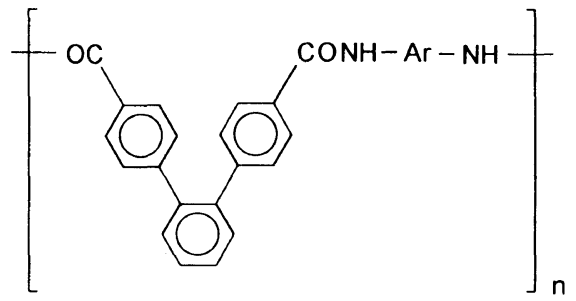

4

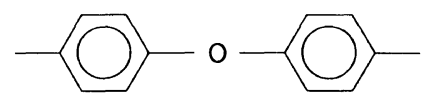

c
Table I. Data for prepared polyamides 4

\begin{tabular}{ccccc}
\hline \multirow{2}{*}{ Polymer } & $\begin{array}{c}\text { Acid } \\
\text { acceptor }\end{array}$ & Yield & & $\eta_{\text {inh }}{ }^{\mathrm{b}}$ \\
\cline { 3 - 3 } & & $\%$ & & $\mathrm{dlg}^{-1}$ \\
\hline $\mathbf{4 a}$ & LC & 93.2 & & 0.23 \\
$\mathbf{4 a}$ & PO & 96.9 & & 0.41 \\
$\mathbf{4 c}$ & PO & 98.9 & & 1.17 \\
& PO & 96.0 & & 0.78
\end{tabular}

a LC, lithium carbonate; PO, propylene oxide.

b Inherent viscosity measured in concd sulfuric acid $\left(0.50 \mathrm{~g} \mathrm{dl}^{-1}\right)$ at $30^{\circ} \mathrm{C}$. ene oxide as a acid acceptor was higher than that with lithium carbonate. Therefore, propylene oxide was used in the polymerization of other polyamides. All polyamides were obtained in quantitative yields. Inherent viscosities of polyamides were found to be in the range of $0.41-1.17 \mathrm{dl} \mathrm{g}^{-1}$.

The solubilities in organic solvents are summarized in Table II. The solubility of polyamide 4a was good; it was soluble in pyridine, $m$-cresol, $N, N$-dimethylacetamide (DMAc), 1-methyl-2-pyrrolidone (NMP), hex- 
Table II. Solubilities of polyamides ${ }^{\mathbf{a}}$

\begin{tabular}{|c|c|c|c|c|c|c|c|c|c|c|}
\hline \multicolumn{2}{|c|}{ Polymer } & $\mathrm{CHO}$ & Py & $m$-Cre & DMAc & NMP & HMPA & DMF & DMSO & $\mathrm{H}_{2} \mathrm{SO}_{4}$ \\
\hline \multirow{3}{*}{2} & $\mathbf{a}$ & $(+)$ & + & + & + & + & + & + & + & + \\
\hline & b & $( \pm)$ & - & $(+)$ & + & + & + & $(+)$ & + & + \\
\hline & c & \pm & $(+)$ & + & + & + & $(+)$ & SW & + & + \\
\hline \multirow{3}{*}{4} & $\mathbf{a}$ & \pm & + & + & + & + & $(+)$ & $(+)$ & + & + \\
\hline & b & - & - & - & $+t^{b}$ & $t^{b}$ & \pm & - & - & + \\
\hline & c & \pm & \pm & \pm & \pm & + & + & \pm & \pm & + \\
\hline
\end{tabular}

a Measured at $0.020 \mathrm{~g} \mathrm{dl}^{-1}$. Data in parenthese are those obtained on heating.

CHO, Cyclohexanone; Py, pyridine; $m$-Cre, $m$-cresol; DMAc, dimethylacetamide; NMP, 1-methyl-2-pyrrolidone, HMPA, hexamethylphosphoric triamide; DMF, dimethylformamide; DMSO, dimethylsulfoxide.

+ , soluble; \pm , partially soluble; - , insoluble; $S W$, swelling.

b Lithium chloride was added.

Table III. Thermal properties of polyamides

\begin{tabular}{|c|c|c|c|c|}
\hline \multirow{2}{*}{\multicolumn{2}{|c|}{ Polymer }} & $T_{\mathrm{g}}^{\mathbf{a}}$ & $T_{\mathrm{d}}^{\mathrm{b}}$ & \multirow{2}{*}{$\begin{array}{l}\text { Residual } \\
\text { weight at } \\
600^{\circ} \mathrm{C} / \%^{\mathrm{c}}\end{array}$} \\
\hline & & ${ }^{\circ} \mathrm{C}$ & ${ }^{\circ} \mathrm{C}$ & \\
\hline \multirow{3}{*}{2} & $\mathbf{a}$ & 283 & 442 & 58 \\
\hline & $\mathbf{b}$ & 289 & 462 & 57 \\
\hline & c & 283 & 446 & - \\
\hline \multirow{3}{*}{4} & $\mathbf{a}$ & 283 & 445 & 56 \\
\hline & b & 333 & 466 & 53 \\
\hline & c & 281 & 452 & 52 \\
\hline
\end{tabular}

a Measured by differntial scanning calorimetry (DSC) (heating rate $10 \mathrm{~K} \mathrm{~min}^{-1}$ in nitrogen atmosphere).

b Temperature at 5\% weight loss was determined by thermogravimetry (TG) (heating rate $10 \mathrm{~K} \mathrm{~min}^{-1}$ in nitrogen atmosphere)

c Determined by TG.

amethylphosphoric triamide (HMPA), dimethylformamide (DMF), dimethylsulfoxide (DMSO), and concd sulfuric acid. Polyamide 4c was soluble in NMP, HMPA, and concd sulfuric acid. But, polyamide $\mathbf{4 b}$ was soluble only in concd sulfuric acid.

The thermal behavior of the polyamides 4 is shown in Table III. Glass transition temperatures $\left(T_{\mathrm{g}} \mathrm{s}\right)$ were determined by differential scanning calorimetry (DSC). $T_{\mathrm{g}}$ of polyamide $4 \mathrm{a}$ was $283^{\circ} \mathrm{C}$ and that of $4 \mathrm{c}, 281^{\circ} \mathrm{C}$. However, $T_{\mathrm{g}}$ of $4 \mathrm{~b}$ was highest with a value of $333^{\circ} \mathrm{C}$. The temperatures at $5 \%$ weight loss $\left(T_{\mathrm{d}} \mathrm{s}\right)$ determined by thermogravimetry (TG) ranged from 445 to $466^{\circ} \mathrm{C}$. Residual weights at $600^{\circ} \mathrm{C}$ were also determined by TG. We found these values to range between $52-56 \%$. Thus, polyamides 4 indicated high thermal stability. This was attributed to the rigidity of $4,4^{\prime \prime}-o$ terphenyldiyl structure. X-Ray diffraction studies revealed that all polyamides 4 were amorphous. It was concluded that the amorphous nature of the polyamides was due to the introduction of the zigzag structure of $4,4^{\prime \prime}$-o-terphenyldiyl unit to the polyamide backbone.

The properties of polyamides 4 were compared with those of corresponding polyamides 2 which were prepared from 4,4"-diamino-oterphenyl. The solubility of $\mathbf{4 a}$ was as good as that of $2 a$ while $4 b$ and $4 c$ were less soluble than $\mathbf{2 b}$ and $\mathbf{2 c}$. In particular, the solubility of polyamide $4 \mathrm{~b}$ was much lower. Thermal stabilities of polyamides $\mathbf{4 a}$ and $\mathbf{4 c}$ were as high as those of $2 \mathbf{a}$ and $2 \mathbf{c}$. However, that of $\mathbf{4 b}$ was higher than that of $\mathbf{2 b}$. This characteristic relation found between the properties of $\mathbf{4 b}$ and those of $\mathbf{2 b}$ differed from the results of Dine-Hart ${ }^{9}$ or our previous reports. ${ }^{2,3}$ DineHart reported ${ }^{9}$ that the softening temperature of polyamide prepared from $o$-phenylenediamine and terephthaloyl dichloride was higher than that of polyamide synthesized from $p$-phenylenediamine and phthaloyl dichloride. 
We reported $^{3}$ that the thermal stability of polyamide prepared from 2,3-bis(4-aminophenyl)quinoxaline and terephthalic acid was higher than that of 4,4'-(2,3-quinoxalinediyl)dibenzoyl dichloride and $p$-phenylenediamine. This suggests that the introduction of a rigid and zigzag structure such as a 1,2-arylene unit to the diamine unit of polyamide backbone is more effective in maintaining high thermal stability rather than the addition of a dicarboxylic acid unit. However, for the combination of $4,4^{\prime \prime}-o$-terphenyldiyl unit and 1,4-arylene unit, as mentioned above, the introduction of $4,4^{\prime \prime}$-o-terphenyldiyl units to the dicarboxylic acid maintained higher thermal stabilities than the diamine unit but lowered the solubility. Dine-Hart reported ${ }^{9}$ the introduction of 1,2-arylene unit to the aromatic polyamide might cause an increase of steric hindrance and intramolecular hydrogen bonding and lowering of the thermal stability was attributed to these factors. But, we conclude that it is difficult for $\mathbf{4 b}$ to form intramolecular hydrogen bonds due to steric bulkiness and that some other factors are responsible for the lowering of the solubility of $\mathbf{4 b}$.

\section{EXPERIMENTAL}

\section{Monomer}

All diamines were obtained commercially. $p$-Phenylenediamine and $m$-phenylenediamine were distilled under reduced pressure. 4,4'Oxydianiline was recrystallized from dry ethanol. 4,4"-o-Terphenyldicarbonyl dichloride ${ }^{6}$ (3) was synthesized from 4,4"-dibromo-oterphenyl ${ }^{7}$ as the starting material according to the method ${ }^{6}$ of Rossa et al. Crude products were recrystallized from dry toluene. Yield $48.0 \%$. mp $169.1^{\circ} \mathrm{C}$ (DTA) (lit. ${ }^{6} 151$ $\left.154^{\circ} \mathrm{C}\right)$, white needles. IR ( $\mathrm{KBr}$ disk): 1770 $\mathrm{cm}^{-1}(\mathrm{C}=\mathrm{O})$. Anal. Calcd for $\left(\mathrm{C}_{20} \mathrm{H}_{12} \mathrm{Cl}_{2} \mathrm{O}_{2}\right)$ (355.2): C, 67.63\%; H, 3.40\%. Found: C, $67.85 \% ; \mathrm{H}, 4.01 \%$.

$N, N^{\prime}$-Diphenyl-4,4"'-o-terphenyldicarboxamide (model compound): In a $10-\mathrm{ml}$ four- necked flask equipped with a reflux condenser and a nitrogen gas inlet were placed $0.174 \mathrm{~g}$ of aniline, $3.0 \mathrm{ml}$ of NMP and a magnetic stirrer bar. The mixture was cooled to $-20^{\circ} \mathrm{C}$ and stirred until all ingredients were dissolved. Then, $0.78 \mathrm{ml}$ of propylene oxide and $0.332 \mathrm{~g}$ of 3 were added and stirred for $2 \mathrm{~h}$. The mixture was stirred at room temperature for $5 \mathrm{~h}$ and then poured into $50 \%$ aqueous methanol. The precipitates were filtrated and dried under reduced pressure at $60^{\circ} \mathrm{C}$. Crude products were recrystallized from cyclohexanone. Yield 95.7\% . mp $337^{\circ} \mathrm{C}$ (DTA). IR (KBr disk): 1648 , $1538 \mathrm{~cm}^{-1}$ (amide I, II). Anal. Calcd for $\left(\mathrm{C}_{32} \mathrm{H}_{24} \mathrm{O}_{2} \mathrm{~N}_{2}\right)$ (468.5): C, 82.03\%; H, 5.16\%; N, $5.98 \%$. Found: C, $81.74 \% ; H, 5.11 \%$; $5.90 \%$.

Polycondensations were conducted by the conventional low-temperature solution meth$\mathrm{od}^{8}$ in NMP with lithium chloride and propylene oxide as hydrogen chloride acceptors. A typical procedure is as follows: In a $10-\mathrm{ml}$ reaction tube equipped with a nitrogen gas inlet having a calcium chloride tube were placed $0.1081 \mathrm{~g}$ of $p$-phenylenediamine, 0.1503 $\mathrm{g}$ of lithium chloride and $3.0 \mathrm{ml}$ of NMP. The mixture was stirred to dissolve the solids, cooled to $-20^{\circ} \mathrm{C}$, and then $0.3552 \mathrm{~g}$ of 3 and $0.78 \mathrm{ml}$ of propylene oxide were added.' The mixture was stirred at $-20^{\circ} \mathrm{C}$ for $2 \mathrm{~h}$, and at room temperature for $5 \mathrm{~h}$. The reaction mixture was poured into aqueous methanol $(\mathrm{MeOH}$ : $\mathrm{H}_{2} \mathrm{O}=1: 1$ in volume), and the precipitates were collected with a glass filter $(3 \mathrm{G})$, washed with methanol and dried under reduced pressure at $60^{\circ} \mathrm{C}$. Yield $98.9 \% . \eta_{\text {inh }}=1.17 \mathrm{dlg}^{-1}$ $\left(0.50 \mathrm{~g} \mathrm{dl}^{-1}\right.$ concd $\mathrm{H}_{2} \mathrm{SO}_{4}$ at $\left.30^{\circ} \mathrm{C}\right)$. IR $(\mathrm{KBr}$ disk): 1642, $1514 \mathrm{~cm}^{-1}$. Anal. Calcd for $\left(\mathrm{C}_{26} \mathrm{H}_{18} \mathrm{~N}_{2} \mathrm{O}_{2}\right)_{n} \quad(390.4)_{n}: \mathrm{C}, \quad 79.98 \% ; \mathrm{H}$, $4.65 \%$; N, 7.17\%. Found: C, 77.23\%; $\mathrm{H}$, $4.68 \%$; $;$; $6.78 \%$. Other polyamides were synthesized by a similar procedure.

\section{Measurements}

$T_{\mathrm{g}} \mathrm{s}$ were determined by DSC (Rigaku Denki Thermal analysis $8055 \mathrm{D} 1) . T_{\mathrm{d}} \mathrm{s}$ and residual 
weights at $600^{\circ} \mathrm{C}$ were determined by TG-DTA (Mac Science TG-DTA 2000). IR spectra were recorded on a Hitachi 270-30 spectrophotometer. Wide angle X-Ray diffraction patterns were obtained for specimens on a Rigaku Denki XG X-ray diffraction apparatus with $\mathrm{Cu}-K_{\alpha}$ radiation $(25 \mathrm{kV}, 10 \mathrm{~mA})$.

Acknowledgment. We thank the Chemical Analysis Center, Chiba University, for conducting the elemental analyses.

\section{REFERENCES}

1. P. E. Cassidy, "Thermally Stable Polymers," Dekker, New York, N.Y., 1980.
2. F. Akutsu, H. Hirata, H. Hayashi, M. Miura, and K. Nagakubo, Makromol. Chem., Rapid Commun., 6, 215 (1985).

3. F. Akutsu, K. Matsuo, K. Naruchi, and M. Miura, Polym. Commun., 30, 182 (1989).

4. F. Akutsu, T. Kataoka, K. Naruchi, M. Miura, and K. Nagakubo, Polymer, 28, 1787 (1987).

5. Y. Kasashima, H. Kumada, K. Yamamoto, F. Akutsu, K. Naruchi, and M. Miura, Polymer, submitted for publication.

6. L. Rossa and F. Vogtle, Liebigs Ann. Chem., 459 (1981).

7. H. Meyer and H. A. Staab, Liebigs Ann. Chem., 724, 30 (1969).

8. P. W. Morgan, "Condensation Polymers by Interfacial and Solution Methods," Interscience, New York, N.Y., 1965.

9. R. A. Dine-Hart, B. J. C. Moore, and W. W. Wright, J. Polym. Sci., B, 2, 369 (1964). 